\title{
Effect of surface treatment on the fatigue strength of additive manufactured Ti6Al4V alloy
}

\author{
Carlos Navarro, Jesús Vázquez, Jaime Domínguez \\ University of Seville, Spain \\ cnp@us.es,jesusvaleo@us.es,jaime@us.es
}

\author{
Antonio Periñán, Marta Herrera García, Fernando Lasagni \\ Advanced Center for Aerospace Technologies (CATEC), Seville, Spain \\ aperinan@catec.aero,mherrera@catec.aero,flasagni@catec.aero
}

Simon Bernarding, Sebastian Slawik, Frank Mücklich

University of Saarlandes, Germany

bernarding.simon@gmail.com,s.slawik@mx.uni-saarland.de,muecke@matsci.uni-sb.de

Francisco Boby, Lloyd Hackel

Curtiss Wright Surface Technologies, Metal Improvement Company, Seville, Spain

Francisco.Boby@cwst.com

\begin{abstract}
Different alloys can be used for Additive Manufacturing (AM) with good structural strength. Among the titanium alloys, Ti6Al4V is the most used, especially for aerospace applications. There have been many analyses of the mechanical properties of additive manufactured Ti-6Al-4V with very good static strength results in general. However, there are still some difficulties to get fatigue properties close enough to the ones of specimens manufactured using traditional processes

Considering the high effect of surface roughness on the fatigue strength of AM specimens, this work deals with the effect produced by some surface treatments on the fatigue properties. Five treatments have been used for comparison. All specimens were annealed previously to reduce residual stresses, as well as sand blasted to reduce the roughness. The treatments considered are: 1) no treatment after annealing and sand blasting; 2) shot peening; 3) shot peening plus Chemical Assisted Surface Enhancement (CASE); 4) laser shock peening, and 5) HIP. After fatigue testing, a comparison of the results has been carried out. It was found that laser peening produced the best results, followed by shot peening plus CASE and shot peening, with the lowest strength produced by HIP as well as just sand blasting after thermal treatment.
\end{abstract}

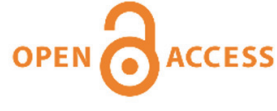

Citation: Navarro, C., Vázquez, J. Domínguez, J., Periñán, A., García, M. H., Lasagni, F., Bernarding, S., Slawik, S., Mücklich, F., Boby, F., Hackel, L., Effect of surface treatment on the fatigue strength of additive manufactured Ti6Al4V alloy , Frattura ed Integrità Strutturale, 53 (2020) $337-344$.

Received: 06.12.2019

Accepted: 22.05 .2020

Published: 01.07.2020

Copyright: (C) 2020 This is an open access article under the terms of the CC-BY 4.0, which permits unrestricted use, distribution, and reproduction in any medium, provided the original author and source are credited. 
KEYWORDS. Additive manufacturing; Fatigue strength of AM elements; Shoot peening; Laser shock peening; Superfinishing; Fatigue strength improvement.

\section{INTRODUCTION}

A dditive manufacturing (AM) of metal parts is a relatively new technology, which is developing very fast. Different metal alloys are used for AM with relatively good strength. Stainless steels, cobalt-chrome, aluminium or titanium alloys are some of those used for structural proposes. Among the titanium alloys, T16Al4V is probably the most used, especially for aerospace applications. Specimens manufactured by AM are used since some years ago in satellites and launchers. They allow reducing the weight, not only because the low density material used, but also because the possibility of taking advantages of topological optimization, presenting monotonic mechanical properties similar to specimens manufactured through traditional technologies like casting. However, in the case of fatigue, AM elements still have problems of strength and reliability [1-3] and that prevents their application in the aeronautical industry, where the reliability is one of the main concerns. The porosity, residual stresses and anisotropy of the additive manufactured specimens as well as the surface roughness and microstructure, which frequently is not well controlled, make the fatigue strength of the elements an issue where there is a lot of work to be done in order to improve this mechanical property and the reliability.

Selective Laser Melting (SLM) is one of the most used AM techniques for Ti6Al4V alloy. The main features regarding fatigue of the work specimens made by this procedure are, as afore said, residual stresses, porosity, roughness, nonuniform microstructure and anisotropy [4-7], which reduce the fatigue strength and increase the scatter of the fatigue lives produced for the same cyclic load applied to different specimens taken from the same manufacturing batch. In addition to select the optimum manufacturing parameters to reduce defects, anisotropy, residual stresses, etc., several mechanical, thermo-mechanical and thermal treatments have been proposed to improve the strength and reduce the scatter [8-20]. These range from annealing or sand blasting to machining [9-13], Hot Isostatic Pressing (HIP) [13-16] or shot peening [17-19], or any combination of them [20]. Many experimental analysis have been published about the effect of these treatments on the fatigue strength, but mainly dedicated to the effect of thermal treatments, machining or HIP or combination of them [8-16]] and only a few about the effect of other surface treatment like shot or laser peening [17-20]. Actually, two of these works only consider the effect of shot peening on roughness, and on residual stresses and microhardness profiles close to the surface, but not directly on the fatigue strength, although they consider that the effect on those parameters will have also a beneficial effect on the fatigue strength. On the other side, Wycisk et al. [19] and Bagherifard et al. [20], analyse directly the effect of shot peening on the fatigue strength of the specimens, Wycisk did it on Ti6Al4V and Bagherifard on AlSi10Mg, with much better results in the case of AlSi10Mg

The main objective of this work is to analyse the effect of some surface treatments on the fatigue strength of additively manufactured specimens. The analysis was made by comparing the fatigue lives obtained with the different treatments selected. The treatments considered are mainly shot peening and laser shock peening. Considering the deleterious effect of roughness, anisotropy and residual stresses existing in the as built elements, before applying any surface treatment, all specimens were sand blasted and annealed. In the case of shot peening, two different surface treatments were considered, one was just shot peening and the other was shot peening followed by a surface treatment called Chemical Assisted Surface Enhancement (CASE), produced by Curtiss-Wright ${ }^{\mathbb{B}}$. This treatment improves the surface finish produced by shot peening. In order to have a reference for the fatigue strength of the surface treated specimens two other treatments were considered. One was just sand blasting and annealing and the other was HIP after sand blasting and annealing. Real as built specimens instead of sandblasted plus annealing could have been used as reference. However, considering that it is well known that the real as buildt conditions produce very poor fatigue strength results and that most applications of SLM manufactured specimens use previous soft surface treatments, to at least clean the specimen surface, as well as heat treatment, it was decided using sandblasted and annealed conditions as reference. The HIP treatment is not actually a surface treatment, but it was included thinking in its use as reference for future analysis of the effect of the combination of HIP with other surface treatments.

This document is organized as follows. First, the manufacturing procedure, treatments considered and test procedure are shown. Following the testing results are described. Those results are discussed trying to understand the effect of the treatments and, finally, some conclusions about the treatments are obtained. 


\section{METHODS AND RESULTS}

\section{Methods}

onsidering that most fatigue failures are initiated at stress concentrations, where there is a stress gradient close to the surface, a series of four point bending tests was designed. 30 prismatic specimens $(80 \times 22 \times 10 \mathrm{~mm}$ with a radius of $2 \mathrm{~mm}$ on corners) were produced by AM with the largest dimension oriented in $\mathrm{Z}$ (vertical) direction in the manufacturing chamber. This direction was selected because it is usually the most unfavourable to resist fatigue due to the orientation of the main defects produced during manufacturing [6,13]. The specimens were manufactured in a Renishaw AM250 SLM system with the following parameters: powder size, 15-45 $\mu \mathrm{m}$; layer thickness, $60 \mu \mathrm{m}$; laser power output $200 \mathrm{~W}$; scan rate, $0.86 \mathrm{~m} / \mathrm{s}$. All specimens were sand blasted and annealed $\left(730^{\circ} \mathrm{C}-2 \mathrm{~h}\right.$; slow cooling in the furnace; high vacuum argon atmosphere) before doing any other treatment or testing directly. The sandblasting treatment was carried out with glass microspheres and the following parameters: direction, $90^{\circ}$ to the surface; exposure time $15 \mathrm{~s}$; work pressure, 5 bar; sandblasting distance; $30 \mathrm{~mm}$. In order to analyse the effect of the treatments, the 30 specimens were divided into five groups of six specimens for each group. Each group was subjected to a different treatment before testing:

Group 1. Specimens were tested directly after sand blasting and annealing, in order to have a reference. This group will also be called "AS BUILT".

Group 2. All specimens were shot peened with the following parameters: $0.6 \mathrm{~mm}$ steel balls; $55-62 \mathrm{HRC}$ balls hardness; intensity $14 \mathrm{~A}$ and $500 \%$ coverage. This group will also be named "SP".

Group 3. In this group, specimens were shot peened before subjected to the treatment called CASE, by Curtis Wright ${ }^{\mathbb{B}}$. In this treatment, parts are placed in an acid solution with non-abrasive ceramic media and the ceramic media is 'excited' using a vibratory bowl. Following, parts are reprocessed in a burnishing solution that restores the chemical stability and polishes the surface. The main objective of this treatment is reducing the roughness produced by shot peening. Actually, the CASE treatment is a kind of what is usually known as REM finishing. This group will also be named "SP+CASE".

Group 4. The specimens were laser shock peened before testing. (wavelength: $1064 \mathrm{~nm}$; pulse length: $10 \mathrm{~ns}$; spot diameter: $2.6 \mathrm{~mm}$; 6 shots at each point; power density $\left.6 \mathrm{GW} / \mathrm{cm}^{2}\right)$. This group will also be named "LP". Figure 1 shows the residual stresses measured in this group.

Group 5. In order to have another reference for fatigue strength to compare the lives obtained with the proposed surface treatments, specimens of this group were treated by HIP $\left(920^{\circ} \mathrm{C}-2 \mathrm{~h} ; 100 \mathrm{MPa}\right.$; inert gas atmosphere). This group will also be named "HIP".

Residual stresses produced by the four treatments were measured by the blind hole drilling technique.In all cases, Vishay Micro-Measurement residual stress rosettes type EA-031RE-120 were used .The drilling and measurement process were carried out using a Sint MTS300 equipment, following the Integral Method [21,22]. A residual stress profile was obtained for each specimen. Figure 1 shows the average residual stress profile in axial direction for each group of specimens and the scatter of the 6 measurement at each point represented by \pm the standard deviation.

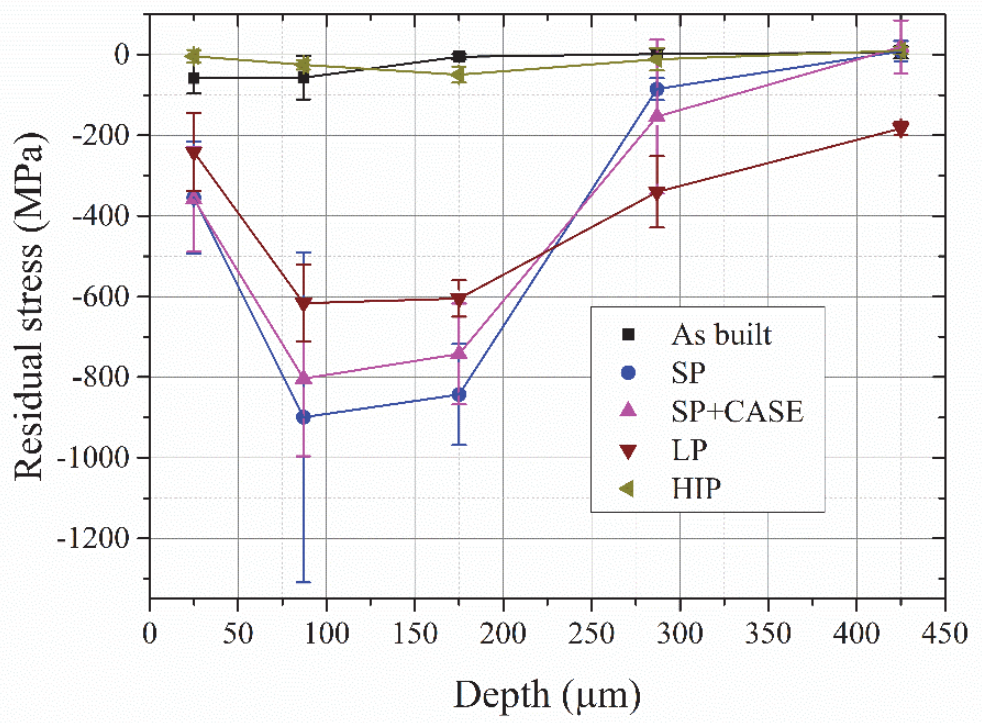

Figure 1: Residual stress produced by sand blasting, shot and laser shock peening, measured by the blind hole drilling technique. 
Considering the large effect of roughness on fatigue, it was measured in all specimens produced. The surface roughness of all specimens was measured by the contact stylus arm with a RC filter technique, using a Mitutoyo Surftest 501 series 178 equipment. The probe tip radius was $5 \mu \mathrm{m}$ and the evaluation length used to obtain $R_{t}$ was $12.5 \mathrm{~mm}$. Table 1 shows the average roughness measured in axial direction $(Z)$ for each group as well as the standard deviation of the measurements carried out in the six specimens of each group. It can be seen that shot peening reduces to almost one third the original roughness, while CASE divides by two the roughness produced by the previous shot peening. Actually, the objective of CASE is to eliminate almost all peaks while maintain troughs, and that is why reduces $R_{a}$ and $R_{t}$ to $50 \%$, approximately. It can be also seen that laser peening, producing a more uniform overpressure on a larger area of the surface for each laser pulse, barely changes the original roughness.

\begin{tabular}{lccccc}
\hline & AS BUILT & SP & SP+CASE & LP & HIP \\
$\mathrm{R}_{\mathrm{a}}(\mu \mathrm{m})$ & $11.7 \pm 1.0$ & $4.6 \pm 2.4$ & $2.7 \pm 0.3$ & $10.2 \pm 1.9$ & $9.8 \pm 1.1$ \\
$\mathrm{R}_{\mathrm{t}}(\mu \mathrm{m})$ & $97.5 \pm 11.8$ & $38.6 \pm 18.6$ & $19.7 \pm 3.4$ & $89.2 \pm 15.3$ & $77.9 \pm 12.3$ \\
\hline
\end{tabular}

Table 1: Average surface roughness of specimens groups after treatments and standard deviation.

Shot peening and laser peening treatments improve the fatigue strength close to the surface but not in the interior [23,24]. Thus, they are useful especially in case of stress gradients close to the surface, like bending, notches or fretting fatigue. Having this into account, all tests in this work have been carried out in four point bending. Figure 2 shows the specimen and loading system in one of these tests, where $h=10 \mathrm{~mm}, L=70 \mathrm{~mm}$ and $t=15 \mathrm{~mm}$. Test frequency was $8 \mathrm{~Hz}$, and stress ratio, $R=0.1$.

\section{Results and Discussion}

Figure 3 shows test fatigue live obtained for all specimens for different stress levels with the lines fitted for every group. Each group is identified with a different symbol, but for each test, the symbol is shown as solid if the failure initiated from the interior and hollow if the failure initiated from the surface. During the initial tests appeared some problems that invalidated two tests. That is why there are only four test results for the AS BUILT treatment. To facilitate the comparison with other data from the literature, the stress amplitude is represented by $\sigma_{f f}$; which is the equivalent maximum stress for a stress ratio $R=-1$. To obtain $\sigma_{e f f}$, the expression proposed by Walker (equation 1) [25,26] was used to transform the results of tests carried out with $R=0,1$ to the equivalent maximum stress with $R=-1$. In equation 1 , the exponent should be fitted for each material and

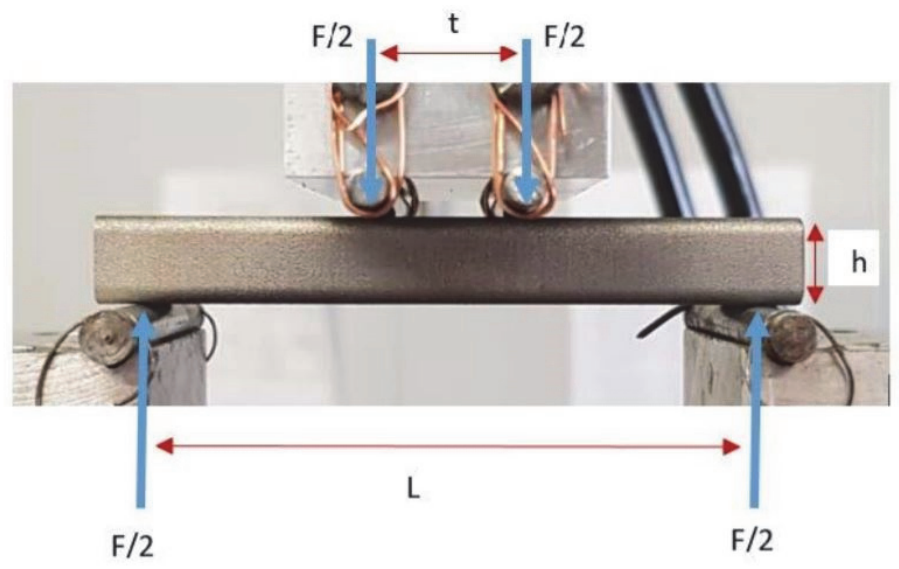

Figure 2: Four point bending tests setup.

$$
\sigma_{e f f}=\sigma_{\max }\left(\frac{1-R}{2}\right)^{0.28}
$$

and $\sigma_{\max }$ is the maximum stress applied in tests with $R=0.1$. In the present case a value of 0.28 was used for the exponent, according to experimental results obtained for conventionally fabricated T16A14V specimens and uniaxially tested with stress ratios ranging from $R=-0.5$ to $R=0.5[27]$ 
From an initial view, it can be seen that HIP and AS BUILT groups are clearly less resistant than other groups. The SP group shows a higher strength, especially for high cycle fatigue; CASE increases this strength with near ten times the lives presented by SP. Finally, LP group shows the best results among all groups. Considering the initiation point of the specimens, all specimens of AS BUILT group initiated the crack on the surface, as well as the HIPed specimens. In the case of shot peened and LP, all specimens failed from the interior, but one, which failed from a defect on the surface, for SP, and on the rounded corner, for LP. All SP+CASE specimens failed with cracks initiated in the interior.

The results for HIPed specimens are very similar to those obtained by Kasperovich and Hausmann [28] with as built surface but HIPed specimens. This low strength can be understood considering that HIP does not eliminate or reduce the surface defects $[11,15,29,30]$. So the crack initiates similarly than in the case of AS BUILT specimens. Tests with HIPed and surface finished specimens are planned for the future, where a high improvement of the fatigue strength is expected, as occurred to Kasperovich and Hausmann with HIPed and machined specimens.

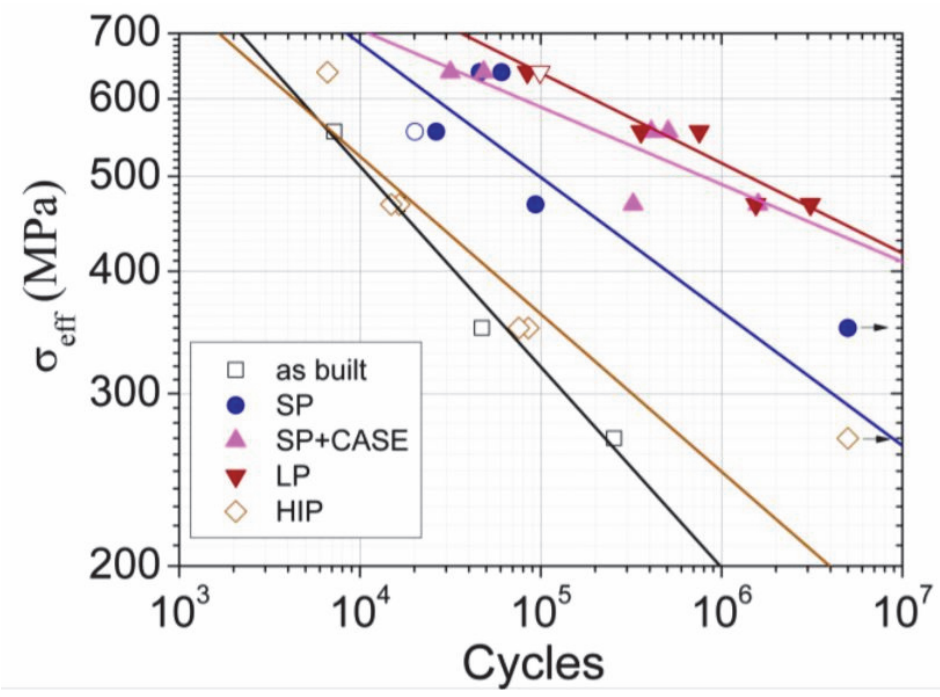

Figure 3: Fatigue test results. Each group is identified with a different symbol. Symbols are shown as solid for failures initiated from the interior and hollow for failures initiated from the surface

Regarding the shot peened specimens, results are in the same line that those obtained by Bagherifard et al. [20] for Al10SiMg, with a clear improvement of the strength. In Ti6Al4V specimens the results are also similar to those obtained by Wycisk et al [19] under axial loads. As far as authors know there are not results in the literature for the other twe surface treatment considered here.

Figure 4 depicts two fracture surfaces with the initiation points marked by arrows. Figure 5 shows SEM images of the initial defects of two of the specimens tested, one produced by lack of fusion and the other a gas pore. Figure 6 represents the position of each initiation point for all specimens that failed with an initiation point at the interior. It can be seen that the initiation point for SP is the surface or at any defect beneath it, while for SP+CASE all cracks initiate beneath the surface. The improvement of the strength produced by SP+CASE compared to SP could be explained because the roughness and the deleterious effect of shot peening on the surface, which also produces small micro cracks, while the CASE treatment reduces the roughness and eliminates those micro cracks. The improvement of the surface finish together with the residual compressive stress field close to the surface eliminates the crack initiation produced by the surface defects. Also, the elimination or reduction of the microcracks due to the CASE treatment, as well as the reduction of the effect of roughness on the stresses very near to the surface make the cracks to initiate deeper, where the stresses are lower because the stress gradient produced by bending and the residual compressive stresses in that zone, which are higher.

Regarding laser peening, the increase of the fatigue strength relative to the other two treatments could be explained by two reasons. On one side, the increase of the depth and width of the residual compressive stress field make the surface initial cracks to stop, allowing growing only cracks initiated below the residual stress field. On the other side, the deeper initiation points means lower stresses in the initiation zone and, so, higher fatigue lives. 

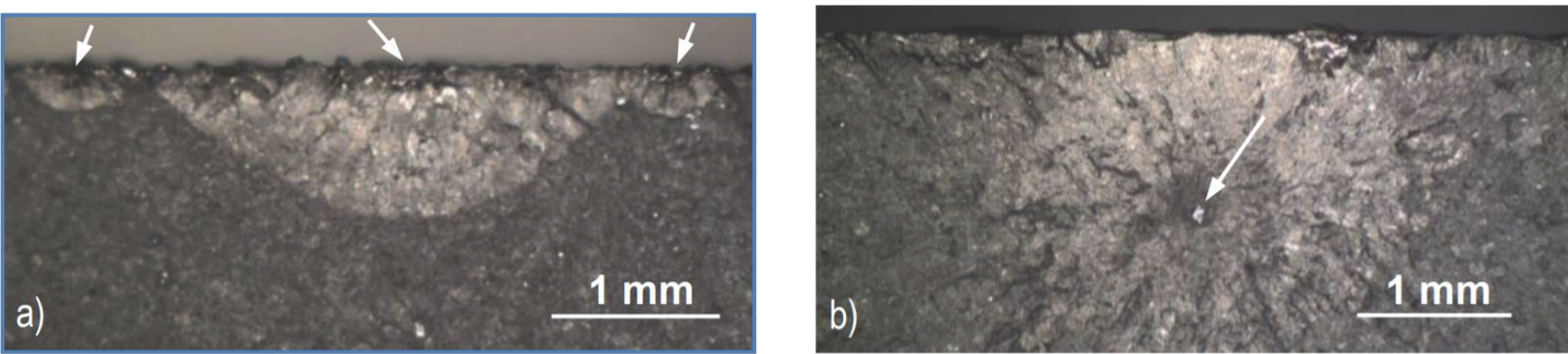

Figure 4: Details of initiation points on fracture surface of specimens: a) B1S4 Sup (as built, $N_{f}=16214$ cycles); b) B4S31 (laser shock peened, $N_{f}=3099304$ cycles)
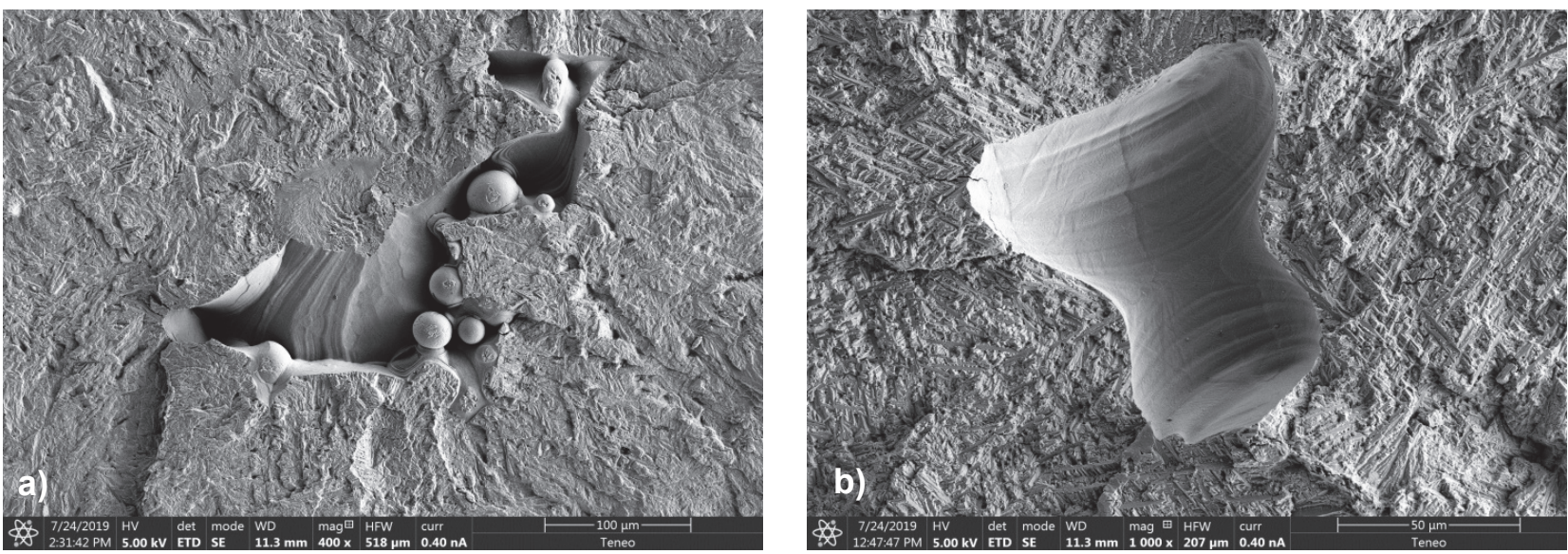

Figure 5: SEM images of two initial defects on fracture surface of specimens: a) B1S9Inf (shot peened, $N_{f}=45992 \mathrm{cycles}$ ); b) B4S32 (laser shock peened, $N_{f}=753603$ cycles)

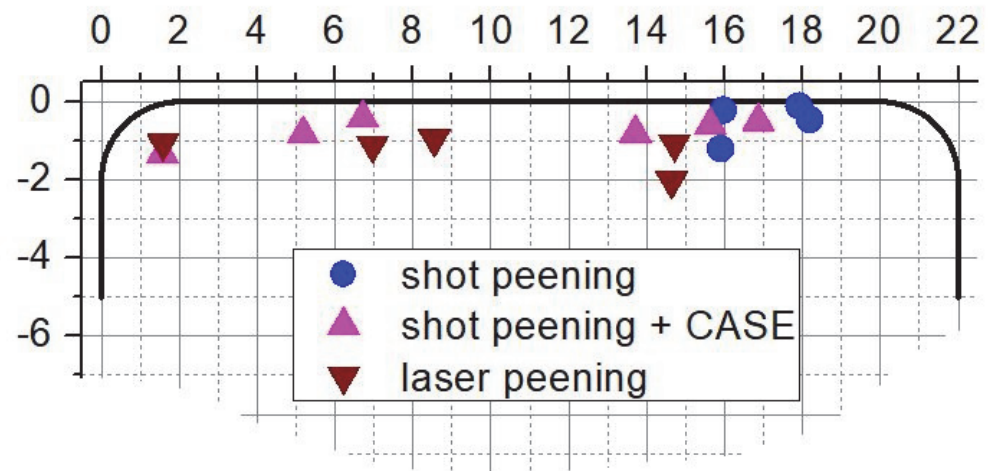

Figure 6: Location of the crack initiation in each test where the fail initiated from an interior defect. Distances in $\mathrm{mm}$.

\section{CONCLUSIONS}

ר

his paper shows the improvement of fatigue strength obtained with different treatments (shot peening, shot peening+CASE, laser peening, HIP) in Ti6Al4V specimens made using additive manufacturing. These treatments have mainly three effects: Surface roughness modification, compressive residual stresses and decreasing pore size (only HIP) [14-16]. The last treatment has little effect on fatigue life. The reason is that due to the stress gradient the cracks initiate from the surface and the surface roughness in the as built specimens and in the HIP specimens is similar. The shot peened specimens experiment a ten fold increase in fatigue life and most initiation points from the interior due to the residual stresses, but due to the high roughness and possible damage due to the treatment there is one crack starting 
from the surface. The specimens with shot peening+CASE have the same residual stresses and a smoother surface, improving then fatigue life and having all the initiation points at the interior. Finally, the laser peening specimens have a high surface roughness but a different residual stress distribution which produces the highest fatigue strength. Other parameters that may influence fatigue behavior as the microstructure have not been studied at this point.

\section{REFERENCES}

[1] Daniewicz, S.R., Shamsaei, N. (2017). An Introduction to the fracture and Fatigue Behavior of Additive Manufactured Parts, International Journal of Fatigue, 94, pp. 167.

[2] Daniewicz, S.R., Johnson, A., Thompson, S. M. and Shamsaei, N. (2018). Structural Integrity of Additive Manufactured Parts, in Laser-Based Additive Manufacturing of Metal Parts, L. Bian, N. Shamsaei y J. M. Usher (eds.), CRC Press, pp. 111-140

[3] Gorelik, M. (2017). Additive Manufacturing in the Context of Structural Integrity, International Journal of Fatigue, 94, pp. $168-177$.

[4] Galarraga, H., Lados, D. A., Dehoff, R. R., Kirka, M. M. and Nandwana, P. (2016). Effects of the microstructure and porosity on properties of Ti-6Al-4VELI alloy fabricated by electron beam melting (EBM), Additive Manufacturing 10 , pp. $47-57$.

[5] Nicoletto, G. (2017). Anisotropic high cycle fatigue behavior of Ti-6Al-4V obtained by powder bed laser fusion, International Journal of Fatigue 94, pp. 255-262.

[6] Yadollahi, A and Shamsaei, N. (2017). Additive manufacturing of fatigue resistant materials: Challenges and opportunities, International Journal of Fatigue 98, pp. 14-31.

[7] Mercelis, P. and Kruth, J. P. (2006). Residual stresses in selective laser sintering and selective laser melting, Rapid Prototyping Journal, 12, pp. 254-265.

[8] Seifi, M., Salem, A., Satko, D., Shaffer, J. and Lewandowski, J. J. (2017) Defect Distribution and Microstructure heterogeneity Effects on Fracture Resistance and Fatigue Behavior of EBM Ti-6Al-4V, International Journal of Fatigue, 94, pp. 263-287.

[9] Leuders, S., Thone, M., Riemer, A., Niendorf, T., Troster, T., Richard, H. A. and Maier, H. J. (2013). On the Mechanical Behaviour of Titanium Alloy TiAl6V4 Manufactured by Selective Laser Melting: Fatigue Resistance and Crack Growth Performance, International Journal of Fatigue, 48, pp. 300-307.

[10] Gong, H., Rafi, K., Starr, T.and Stucker, B. (2012) Effect of Defects on Fatigue of As Built Ti6Al4V Parts Fabricated by Selective Lasser Melting, Solid Freeform Fabrication Symposium, pp. 499-506.

[11] Li, P., Warner, D. H., Fatemi, A. and Phan, N. (2016). Critical assessment of the fatigue performance of additively manufactured Ti-6Al-4V and perspective for future research, International Journal of Fatigue, 85, pp. $130-143$.

[12] Wycisk, E., Solbach, A., Siddique, S., Herzog, D., Walther, F. and Emmelmann, C. (2014). Effects of defects in Laser Additive Manufactured Ti-6Al-4V on Fatigue Properties, Physics Procedia, 56, pp. 371-378.

[13] Shamsaei, N. and Simsiriwong, J. (2017). Fatigue Behaviour of Additively-Manufactured Metallic Parts, Procedia Structural Integrity, 7, pp. 3-10.

[14] Greitemeier, D., Palm, F., Syassen, F. and Melz, T. (2019). Fatigue Performance of Additive Manufactured TiAl6V4 Using Electron and Laser Beam Melting, International Journal of Fatigue, 94, pp. 211-217.

[15] Atkinson, H.V. and Davies, S. (2000). Fundamental Aspects of Hot Isostatic Pressing: an Overview, Metallurgical and Materials Transactions A, 31A, pp. 2981-3000.

[16] Massuo, H., Tanaka, Y., Morokoshi, S., Yagura, H., Uchida, T, Yamamoto, Y and Murakami, Y. (2018). Influence of Defects, surface roughness and HIP on the Fatigue Strength of Ti-6Al-4 Manufactured by Additive Manufacturing, International Journal of Fatigue, 117, pp.163-179.

[17] Maamoun, A.H., Elbestawi, M.A. and Veldhuis, S.C. (2018). Influence of Shot Peening on AlSi10Mg Parts Fabricated by Additive Manufacturing, J. Manuf. Mater. Process. 2, 40, DOI:10.3390/jmmp2030040.

[18] Lesyk, D.A., Martinez, S., Mordyuk, B.N., Dzhemeinsky, V.V., Lamikiz, A. and Prokopenko, G.I. (2020). Postprocessing of the Inconel 718 alloy parts fabricated by selective laser melting: Effects of mechanical surface treatments on surface topography, porosity, hardness and residual stress, Surface and Coatings Technology, 381, 125136. DOI: $10.1016 /$ j.surfcoat.2019.125136.

[19] Wycisk, E., Emmelmann, C., Siddique, S. and Walther, F. (2013). High Cycle Fatigue (HCF) Performance of Ti-6Al4V Alloy Processed by Selective Laser Melting, Advanced Materials Research, 816-817, pp. 134-139. 
[20] Bagherifard, S., Berette, N., Monti, S., Riccio, M., Bandini, M. and Guagliano, M. (2018). On the fatigue strength enhancement of additive manufactured AlSi10Mg parts by mechanical and thermal post-processing, Materials \& Design, 145, pp. 28-41.

[21] Schajer, GS. (1988). Measurement of Non-Uniform Residual Stresses Using the Hole-Drilling Method. Part I-Stress Calculation Procedures. J Eng Mater Technol, 110, pp. 338-343. DOI:10.1115/1.3226059.

[22] Schajer, GS. (1988). Measurement of Non-Uniform Residual Stresses Using the Hole-Drilling Method. Part IIPractical Application of the Integral Method. J Eng Mater Technol, 110, pp. 344-349. DOI:10.1115/1.3226060.

[23] Vázquez, J., Navarro, C. and Domínguez, J. (2012). Experimental Results in Fretting Fatigue with Shot and Laser Peened Al 7075-T651 Specimens, International Journal of Fatigue, 40, pp. 143-153.

[24] Martín, V., Vázquez, J, Navarro, C and Domínguez, J. (2020). Effect of shot peening residual stresses and surface roughness on fretting fatigue strength of Al 7075-T651, Tribology International, 142, 106004.

[25] Walker K. (1970). The effect of stress ratio during crack propagation and fatigue for 2024-T3 and 7075-T6 aluminum. Effects Environ Complex Load History on Fatigue Life, ASTM STP 462, pp. 1-14.

[26] Dowling NE, Calhoun CA, Arcari A. (2009). Mean stress effects in stress-life fatigue and the Walker equation. Fatigue Fract Eng Mater Struct., 32, pp. 163-179.

[27] Metallic Materials Properties Development and Standardization (MMPDS-05), Battelle Memorial Institute; 2010. http://app.knovel.com/hotlink/toc/id:kpMMPDSM11/metallic-materials-properties/metallic-materials-properties.

[28] Kasperovich, G. and Hausmann, J. (2015). Improvement of Fatigue Resistance and Ductility of Ti6Al4V processed by Selective Laser Melting, Journal of Materials Processing Technology, 220, pp.202-214.

[29] Tammas-Williams, S., Withers, P.J., Todd, I and Prangnell, P.B. (2016). The Effectiveness of Hot Isostatic Pressing for Closing Porosity in Titanium Parts Manufactured by Selective Electron Beam melting, Metall and Mat Trans A, 47A, pp. 1939-1946, DOI:10.1007/s11661-016-3429-3.

[30] Shunyu, L., Yung, C. S. (2019). Additive manufacturing of Ti6Al4V alloy: A review, Materials \& Design, 164, 107552, DOI: $10.1016 /$ j.matdes.2018.107552. 